\title{
Study on Mineral Processing of a Refractory Low Grade IImenite Ore
} Haiyun Xie ${ }^{1, a}$,Rongxin Liu, ${ }^{1, b}$, Pengfei Zhang ${ }^{1, c}$,Chao Ding ${ }^{1, ~ d}$,Xiong Tong ${ }^{1, e}$

${ }^{1}$ Faculty of Land Resource Engineering, Kunming University of Science and Technology, Kunming, Yunnan, China, 650093

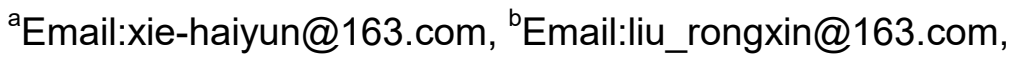

'Email:1540028565@qq.com, dEmail:1822934854@qq.com, eEmail:xiongtong2000@yahoo.com

Communication author:Rongxin Liu,(1994-),Postgraduate, Research Field: Theory and Technology of Mineral processing.

Keywords: ilmenite ore; flotation-magnetic separation; flotation-magnetic-gravity separation Abstract: Aiming at the characteristics of ilmenite ore with a low grade, fine disseminated grain size and containing plenty of mud in Kunming Yunnan, the mineral properties of the ore samples in this area were analyzed and exploratory experiment of mineral processing were researched in this article. The results show that the titanium containing minerals are mainly rutile, the grade of $\mathrm{TiO}_{2}$ account for $4.66 \%$, and followed by ilmenite ore and a small quantity of titanium magnetite. The grade of $44.01 \% \sim 45.64 \%$ and the comprehensive recovery of $33.93 \% \sim 42.14 \% \mathrm{TiO}_{2}$ can be obtained using a combined processing, flotation-magnetic separation processing and flotation-magnetic-gravity separation combined processing are more suitable mineral processing direction, it is a reference significant for the real production.

\section{Introduction}

Titanium resources are rich in China, and its reserves ranking first in the world ${ }^{[1-3]}$. However, China's ilmenite ore generally low grade, the average grade from $5 \%$ to $10 \%{ }^{[4]}$. It is difficult to separation and obtain high grade. At the same time, from the 90's of the 20 century, a growing number of private enterprises exploit mining Titanium sands in Kunming ${ }^{[5]}$. There are serious problems for recovering low grade ilmenite resources. Geological tectonic situation is extremely special in Kangdian axis of the southern section. According to this particularity of the low grade ore, experimental research on mineral processing is given for use the mineral resources effectively. Flotation-magnetic separation and magnetic-flotation-gravity separation process the low grade ilmenite ore provides some basis for effective use of the resources.

\section{Material and Method}

\section{Raw ore composition}

The test of ilmenite ore samples taken from the Kunming, Yunnan. Sample were carried out elemental analysis and phase analysis. The results of the analysis are shown in table 1and table 2.

Table1 Elements analysis results of ilmenite ore

\begin{tabular}{ccccccccc}
\hline Content & $\mathrm{TiO}_{2}$ & $\mathrm{Fe}$ & $\mathrm{CaO}$ & $\mathrm{p}$ & $\mathrm{S}$ & $\mathrm{As}$ & $\mathrm{SiO}_{2}$ & $\mathrm{Al}_{2} \mathrm{O}_{3}$ \\
\hline Percentage $(\%)$ & 4.66 & 15.07 & 0.56 & 0.18 & 0.09 & 0.009 & 38.42 & 15.56 \\
\hline
\end{tabular}

The ore chemistry element analysis results show that The grade of $\mathrm{TiO}_{2}$ is low, accounting for $4.66 \%$, the content of total iron is $15.07 \%$. Hazardous elements such as content of sulphur and arsenic levels are lower, but high phosphorus content of impurities. 
Table2 Mineral phase analysis results of ilmenite ore

\begin{tabular}{cccccc}
\hline Mineral & Ilmenite & Rutile & Titanium magnetite & Silicate and stone & Total \\
\hline $\mathrm{TiO}_{2}$ percentage $(\%)$ & 1.40 & 2.21 & 0.077 & 0.70 & 4.39 \\
$\mathrm{TiO}_{2}$ distribution rate $(\%)$ & 31.91 & 50.38 & 1.76 & 15.95 & 100 \\
\hline
\end{tabular}

According to phase analysis of results, the $\mathrm{TiO}_{2}$ mainly found in rutile and ilmenite, $\mathrm{TiO}_{2}$ account for $82.29 \%$ in these minerals. Therefore, the main mineral processing mineral is rutile and ilmenite. In addition, there are $15.95 \%$ of $\mathrm{TiO}_{2}$ hosted in cutting stone and silicate minerals.

Titanium, iron ore particle size characteristics and particle size distribution

Ore particle size composition of titanium and iron in each size fraction distribution rates are shown in table 3.

Table3 Ore particle size composition of titanium and iron in each size fraction distribution rates

\begin{tabular}{|c|c|c|c|c|c|}
\hline \multirow{2}{*}{ Size $(\mathrm{mm})$} & \multirow{2}{*}{$\gamma(\%)$} & \multicolumn{2}{|c|}{$\beta(\%)$} & \multicolumn{2}{|c|}{ Distribution rate $(\%)$} \\
\hline & & $\mathrm{TiO}_{2}$ & $\mathrm{Fe}$ & $\mathrm{TiO}_{2}$ & $\mathrm{Fe}$ \\
\hline+1 & 1.41 & 3.99 & 17.16 & 1.20 & 1.53 \\
\hline$-1 \sim+0.15$ & 15.45 & 6.39 & 19.69 & 21.08 & 19.25 \\
\hline$-0.15 \sim+0.074$ & 12.14 & 8.79 & 18.80 & 22.80 & 14.45 \\
\hline$-0.074 \sim+0.037$ & 16.92 & 6.52 & 16.69 & 23.60 & 17.87 \\
\hline-0.037 & 54.08 & 2.71 & 13.71 & 31.32 & 46.90 \\
\hline Total & 100.00 & 4.68 & 15.80 & 100.00 & 100.00 \\
\hline
\end{tabular}

Experiment results in table 3 showed that the ilmenite fine particle size mainly $-0.074 \mathrm{~mm}$, accounting for $71 \%$, of which $-0.037 \mathrm{~mm}$ yields of fine particle size fraction accounted for $54.08 \%$, and the grade of $\mathrm{TiO}_{2}$ only occupying $2.71 \%$, indicating that the high mineral mud, containing lots of slime. Also the uneven distribution of titanium in various size, and distribution of titanium is mainly concentrated in the $-0.037 \mathrm{~mm}$ fraction, titanium mineral processing is particularly important in the slime.

\section{Results and Discussion}

\section{Magnetic separation test}

The ore properties shows that the valuable mineral is ilmenite in this samples. Therefore, the weak magnetic separation and high intensity magnetic separation can be carried out after an open circuit grinding. Magnetic model for $\Phi 300 x 1000 \mathrm{~mm}$ drum high intensity permanent magnetic separators and BX weak magnetic separation machines, the experimental flow is shown in Figure 1.

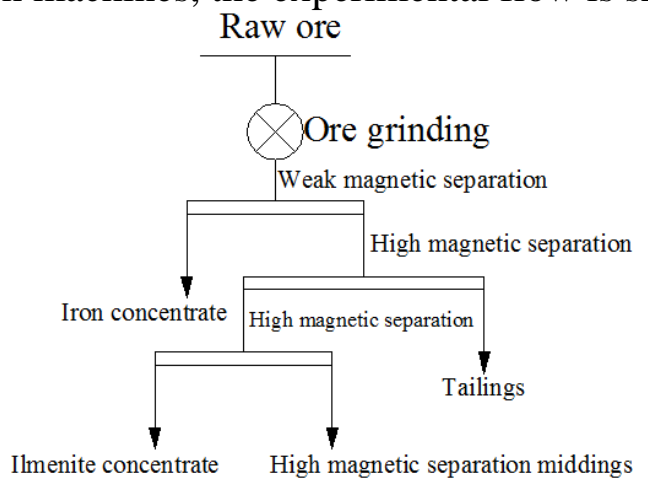

Fig.1 Magnetic separation test flowsheet

The yield of $1.74 \%$ is obtained by the weak magnetic separation, $\mathrm{TiO}_{2}$ occupy $22.34 \%$, and $\mathrm{Fe}$ 
account for $48.87 \%$ containing titanic magnetite concentrate from the test results. Also, the grade of $\mathrm{TiO}_{2}$ occupy $22.55 \%$, and the recovery is $41.13 \%$ by high magnetic separation. Because of the high loss rate of ilmenite, and the low recovery rate, it is necessary to carry out other methods of mineral processing.

\section{Magnetic-Gravity test}

Depending on the nature of ilmenite and associated other mineral density differences ${ }^{[4]}$, weak magnetic and magnetic separation is obtained, and magnetic separation tailings into 6-S table. Experimental flow is shown in Figure 2.

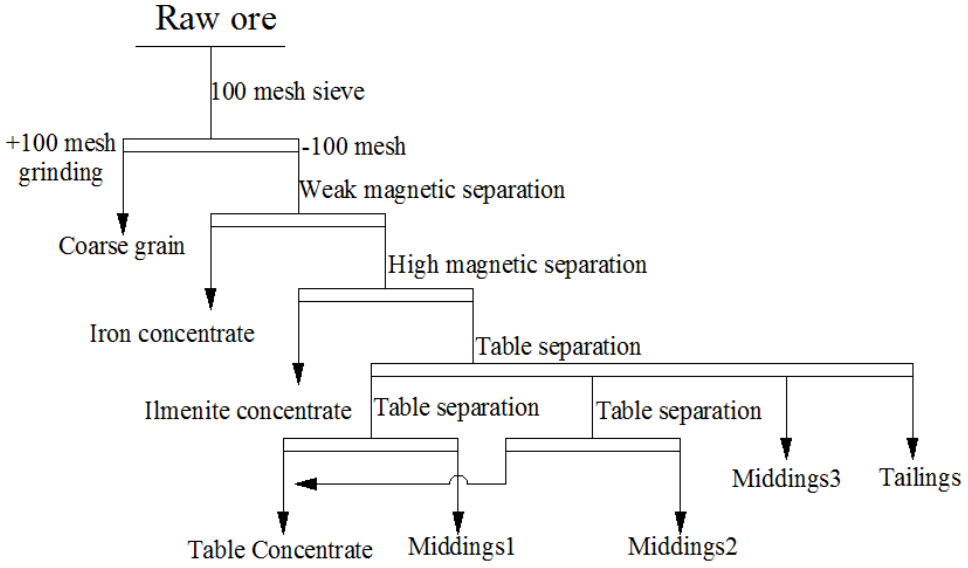

Fig.2 Magnetic gravity test process

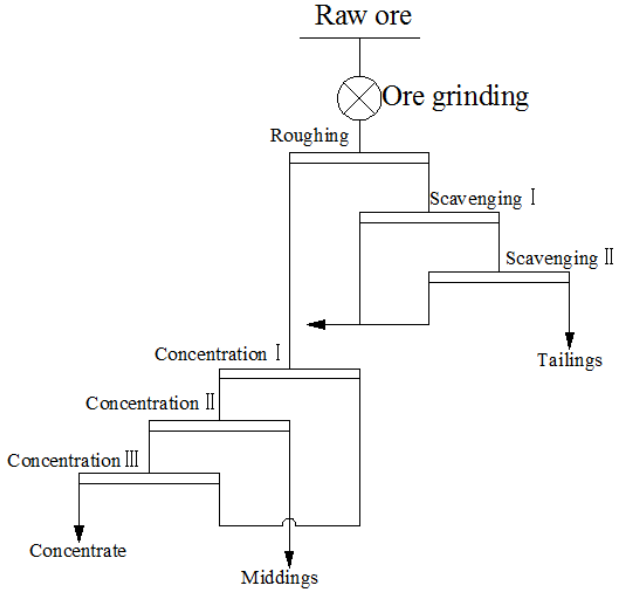

Fig.3 Flotation test process

These results under a microscope suggested that weak magnetic concentrate, black magnetic minerals are reunited and accompained with a small amount of blue-purple and silver shiny particles, most of yellow and reddish brown mineral. Weak magnetic separation can be obtained the yield of rough concentrate account for $4.38 \%$, including $\mathrm{TiO}_{2} 24.42 \%$, $\mathrm{Fe} 44.01 \%$, the recovery rate of iron is $12.4 \%$. Strong magnetic separation can be obtained the grade of $20.37 \%$ ilmenite concentrate and the recovery of ilmenite occupy $46.33 \%$, iron account for $20.37 \%$. There are low grade ilmenite may be due to which some limonite, adherent and gangue minerals.
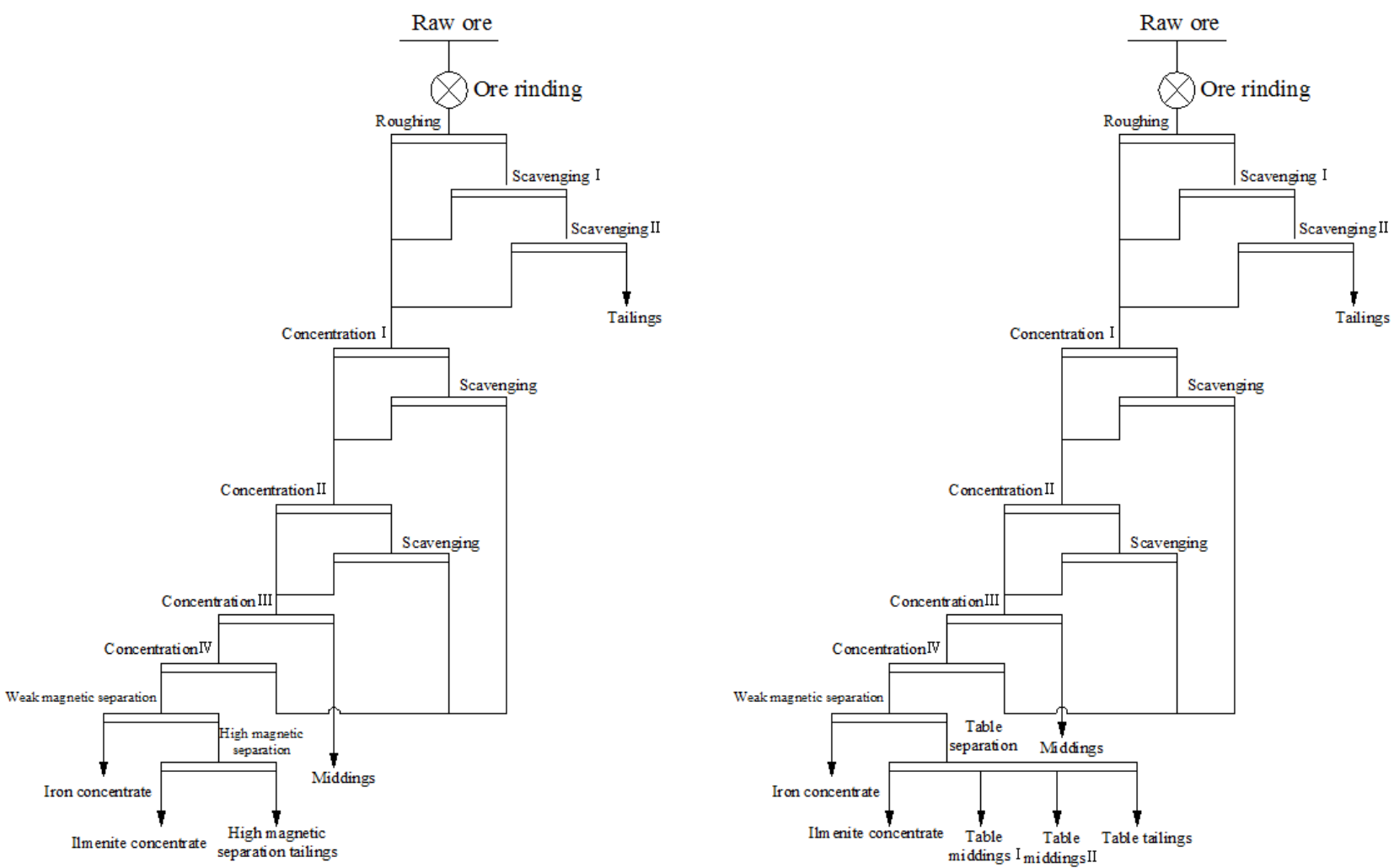

Fig.4 Flotation and magnetic separation test

Fig.5 Flotation and magnetic gravity separation test 


\section{Flotation test}

A single flotation, roughing once and scavenging twice and multiple concentration is adopted, and XDF-1 flotation machine is used, experimental flow is shown in Figure 3.

It can be obtained the grade of ilmenite concentrate containing $\mathrm{TiO}_{2} 21.17 \sim 30.59 \%$, and the recovery occupy $42.12 \% \sim 45.63 \%$ by roughing once, scavenging and multiple selection of flotation process. Single flotation test results show that the ilmenite can be recovered through flotation enrichment and improve the grade of $\mathrm{TiO}_{2}$ in the ilmenite ore.

\section{Flotation and magnetic separation test and flotation-magnetic-gravity separation}

Roughing once, scavenging twice, and four fine flotation separation is used for ilmenite in Kunming. Then, ilmenite concentrate can be obtained by the weak magnetic separation and magnetic separation technology. This objective is further to improve concentrate grade, experimental flow is shown in Figure 4 and Figure 5.

It can be got the grade of ilmenite concentrate containing $\mathrm{TiO}_{2} 45.64 \%$ and the recovery is $20.92 \%$ by flotation-magnetic-gravity separation. These results suggest that we can get the higher grade and better recovery of ilmenite concentrate by using the separation, this process should be studied to obtain stable economic mineral processing indexes.

\section{Conclusions}

(1)The grade of $\mathrm{TiO}_{2}$ account for $14.66 \%$, and $\mathrm{Fe}$ occupy $15.07 \%$, which main minerals are rutile, followed by ilmenite and a small amount of titanic magnetite, lime stone and silicate minerals containing the $\mathrm{TiO}_{2}$ too.

(2)The low grade ilmenite is treated by flotation-magnetic separation and flotation-magnetic separation-gravity separation process, The results of the open circuit test show that the grade of $\mathrm{TiO}_{2}$ in the ilmenite concentrate is $44.01 \% \sim 45.64 \%$, the recovery rate account for $33.93 \% \sim 42.14 \%$. Using combined flowsheet can get a high grade of ilmenite concentrates. Flotation-magnetic combined flowsheet and flotation-magnetic-gravity separation for suitable mineral processing directions.

(3)Due to the high content of the ore fine, mud grave and it is difficult to separate, the research and development process is complex, it is necessary to research for simplify processes, improve indexes and decrease costs in many mineral processing.

\section{Acknowledgements}

This work was financially supported by the Natural Science Foundation of China (Grant No. 51464030).

\section{References:}

[1]Sijie Huang, Zhiyong Ye, Manli You. Mineral processing test of a ilmenite ore in Shanxi[J]. Mineral Engineering: 2012, 41(9): 48-51.

[2]Liping Wang, Gao Wang. Distribution and production status of titanium resources in China[J]. Rare Metals:2004, 28(1): 265-267.

[3]Xian Wu, Jian Zhang. Distribution and characteristics of titanium resources in China[J]. Progress in Titanium Industry:2006, 23(6): 8-12.

[4]Yuanyan Han, Huixin Dai. Study on mineral processing technology of low grade ilmenite ore in Yunnan[J]. Mining and Metallurgy:2010, 19(4): 31-33.

[5]Chuanjing Dai. Resources and origin of ilmenite ore in Kunming area[J]. Yunnan Geology:2010, 29(3): 286-294.

[6]Chuanyao Sun, Ning Ao, Yaoqing Liu. Beneficiation technology for complex refractory ore[M]. BeiJing: Metallurgical Industry Press, 2009. 